\title{
The treatment of constipation in mental hospitals
}

\author{
L. R. C. HAWARD AND H. E. HUGHES-ROBERTS \\ From Graylingwell Hospital, Chichester
}

SYNOPSIS This study investigates the incidence of constipation in two representative mental institutions, and the effect, in one of the hospitals, of restricting the use of laxatives to only one drug, namely, standardized senna (Senokot). The remarkable potentiality of Senokot for long-term re-educative programmes is reflected in the reduction from $44 \%$ of 210 patients receiving various laxatives regularly at the'start of the trial to $8 \%$ after three months' treatment. The special studies showed that chronic psychotics could be freed from enemas and a substantial number (17 out of 24) cured of constipation; 31 patients on insulin therapy required maintenance doses during treatment but all were subsequently cured; of 25 patients with various neurological lesions, 21 were freed of laxative treatment with four only remaining on sub-laxative doses.

There exists a two-way psychosomatic relationship whereby brain and bowel function influence each other. Alvarez (1948), for example, has shown that nervous tension particularly affects the bowel muscles; conversely, Nobbs (1960) has found that a loaded bowel can cause mental confusion in the elderly and that the correction of constipation restores the mental equilibrium. In examining the problems of bowel regularity in a mental hospital we are, therefore, studying a pertinent and not unimportant factor in the patient's psychiatric condition.

The investigation to be described concerns the extent of the problem of constipation in a representative sample of psychiatric patients, the methods of treatment used in certain mental hospitals, and controlled trials of a new preparation with selected patients in special diagnostic categories. In the past, constipation has generally been defined on a temporal basis. For example, Hurst (1937) states that constipation is a condition in which the residue of food ingested during one day is not excreted within the next $\mathbf{4 8}$ hours. Such a conception does not take into consideration those cases with a bowel rhythm giving normal motions every third or fourth day, and it is more physiological to use the definition of Cecil and Loeb (1959) who regard constipation as the passage of unduly hard and dry faecal matter regardless of the time factor or the number of movements. In the present study, which relied in part on the objective assessment of constipation by a large number of psychiatrists each possessing his own idea of what constitutes the disorder, it was found necessary to employ the basis of the actual prescription of an aperient.

\section{INCIDENCE}

Forms were circulated to the pharmacy departments of mental hospitals in England asking for details of the use of laxatives. From the replies it was clear that ward issues ranged from one predominant or a few well-chosen aperients to the whole gamut of laxatives. In some hospitals laxatives were prescribed only by the medical officers; in others they were dispensed by, and at the discretion of, sisters and charge nurses. Table I gives the number of patients treated for constipation during one week in two hospitals,

TABLE I

PATIENTS TREATED FOR CONSTIPATION IN ONE WEEK IN TWO REPRESENTATIVE HOSPITALS

\begin{tabular}{lrr} 
& \multicolumn{2}{l}{ Hospital } \\
\cline { 2 - 3 } & \multicolumn{1}{c}{$\boldsymbol{A}$} & \multicolumn{1}{c}{$\boldsymbol{B}$} \\
\hline Number of beds & 2,219 & 997 \\
Number of patients receiving laxatives & & \\
Male in-patients & 664 & 66 \\
Female in-patients & 833 & 223 \\
Total & 1,497 & 289 \\
Percentage of bedstate & 70 & 30
\end{tabular}


chosen to illustrate extreme attitudes towards constipation. Hospital A provides aperients on request and also 48 hours after the last bowel movement; hospital B dissuades patients from taking aperients and allows them only when an appreciable time has elapsed since defaecation.

In Table II the types of laxative employed in these two hospitals are shown with the quantities pre-

TABLE II

LAXATIVE TREATMENT FOR ONE MONTH PER 1,000 BEDS

\begin{tabular}{llrr} 
Treatment & Unit & \multicolumn{2}{c}{ Hospital } \\
\cline { 3 - 4 } & & \multicolumn{1}{c}{$A$} & \multicolumn{1}{l}{$B$} \\
\hline Enemas & & 460 & 300 \\
Liquid paraffin & Oz. & 80 & 128 \\
Mist. aperient & Oz. & 8,000 & 160 \\
Mist. alba & Oz. & 0 & 150 \\
Mist. phenolphthalein & Oz. & 80 & 0 \\
Saline salts & Doses & 6 & 0 \\
Cascara: Elixir & Oz. & 320 & 0 \\
$\quad$ Tablets & Tablets & 0 & 321 \\
Senna (Senokot) & Tablets & 0 & 319 \\
Colocynth & Tablets & 20 & 0
\end{tabular}

TABLE III

ANALYSIS OF INCIDENCE OF CONSTIPATION BY CAUSES IN MENTAL PATIENTS

A Organic and pathological
(i) Central nervous system pathology
(ii) Hypothyroidism
(iii) Obesity
(iv) Cachexia
(v) Idiopathic megacolon

B Pharmacological

(i) Insulin treatment

(ii) Psychotropic treatment

C Immobile

Chronic mental patients

D Psychological

(a) Primary predisposing factors

(i) Autonomic imbalance

(ii) Personality traits

(iii) Other factors

8

(b) Secondary to mental disorders ${ }^{2}$

(i) Schizophrenic

(ii) Depressive

(iii) Psychoneurotic

(c) With psychogenic dietary problems ${ }^{3}$

(i) Premorbid

(ii) Acute schizophrenia

(iii) Protracted depression

Total cases
17

4 scribed. To make the figures comparable, these have been given as treatments per month per 1,000 beds. The incidence of constipation was then analysed in terms of cause in all patients in hospital A receiving aperients during the study week (column 2 of Table I) and the analysis is shown in Table III.

It will be seen that less than $4 \%$ of the sample suffered with constipation apparently unrelated to their mental state. The significance of the psychological factors existing in other cases will be discussed later.

It will be seen from Table I that the in-patient figures show a sex difference in which significantly more females than males received aperients, whereas in a pilot study conducted at the psychiatric outpatient clinic, it was found that the sex difference was not significant. Unless the in-patient sex difference is a sampling artefact the sex equality in the out-patients suggests that this phenomenon is related to prescribing aperients rather than to taking aperients, and this may indicate an interesting facet of attitudinal differences between male and female nurses. Of those out-patients who reported being constipated, $60 \%$ complained of habitual constipation, while the overall incidence of constipation amongst out-patients (Table IV) is similar to that found by other investigators, e.g., Wager and Melosh (1958).

\section{TABLE IV}

INCIDENCE OF LAXATIVE TAKING IN PSYCHIATRIC OUT-PATIENTS

\begin{tabular}{llc} 
& \multicolumn{2}{l}{ Out-patients } \\
\cline { 2 - 3 } Sample number & $\begin{array}{l}\text { Males } \\
100\end{array}$ & $\begin{array}{l}\text { Females } \\
100\end{array}$ \\
\hline Number taking aperients during study week & 47 & 39 \\
Number taking aperients regularly & 27 & 21
\end{tabular}

An analysis by age and duration, however, produced figures different from those previously reported. Table $V$ illustrates the shift from the middle-aged group to the extreme, and probably reflects the higher medication with constipating psychotropic drugs amongst the younger patients, together with the large number of elderly and relatively immobile patients.

'Constipation arising, before the onset of current mental illness, from psychophysiological factors which characterize the premorbid personality and predispose the organism towards mental disorder.

${ }^{2}$ Constipation arising after onset of a mental disorder as a result of the behavioural symptoms, e.g., psychomotor retardation in melancholia.

${ }^{3}$ In this group the mental disorder has produced abnormal attitudes towards food which eventually lead to chronic constipation, e.g., the schizophrenic possessing delusional ideas concerning the symbolic significance of the ingestion of food, believing it to induce pregnancy.

\begin{tabular}{|c|c|c|c|}
\hline \multicolumn{4}{|c|}{$\begin{array}{c}\text { TABLE V } \\
\text { COMPARISON OF INCIDENCE OF CONSTIPA? }\end{array}$} \\
\hline AGE IN MENTAL & $\begin{array}{l}\text { Under } 25 \\
(\%)\end{array}$ & $\begin{array}{l}25 \text { to } 50 \\
(\%)\end{array}$ & $\begin{array}{l}\text { Over } 50 \\
\text { Years }(\%)\end{array}$ \\
\hline \multirow{2}{*}{$\begin{array}{l}\text { Psychiatric (present study) } \\
\text { Medical/surgical (Lamphier } \\
\text { and Ehrlich, 1957) }\end{array}$} & 27 & 26 & 47 \\
\hline & 14 & 53 & 33 \\
\hline
\end{tabular}




\section{SELECTION OF APERIENT}

It is clear that the efficient treatment of constipation requires the limitation of laxatives to preferably one aperient of general efficacy; the laxative must be inexpensive, easy to administer, and physiological in its action, so that a rational treatment of bowel re-education (in contrast to the symptomatic and temporary relief by purging) can be initiated. Of all the laxatives available, the claims of standardized senna for general use appeared outstanding.

Bulk laxatives containing psyllium and other hydrophylic colloids are contraindicated in constipated subjects with a distended atonic bowel and elsewhere they are of uncertain value (Francillon, 1952). Salines act by increasing the fluid content within the lumen of the bowel, with resultant stimulation of the small as well as the large intestine and are thus unphysiological for regular use.

Castor oil, vegetable laxative tablets N.F., which contain jalap, colocynth, and podophyllin, are irritant purgatives affecting both small and large intestine. Their excessive use leads to serious depletion of sodium and potassium, and they have no place in modern medicine (Coghill, McAllen, and Edwards, 1959; Burgess, 1958).

Liquid paraffin and its emulsions continue to be widely used but this would seem to be due to habit, albeit a bad one. The evidence condemning their use is now overwhelming. Becker (1952) quotes 52 references describing its deleterious effect.

The more recently introduced 'contact' laxatives, such as the bisacodyl substance (marketed 'ethically' as Dulcolax and 'publicly' as Tempo) are relatively expensive and are contraindicated when alkalis are in use. The suppositories have been used with success although little is known of their pharmacology.

\section{THE STIMULANT LAXATIVES}

These include phenolphthalein and the anthracene drugs senna, rhubarb, aloes and cascara.

Phenolphthalein, a pure substance, with a chemical structure having some similarity to that of the anthracene glycosides, is, generally speaking, a safe drug. It can, however, very occasionally give rise to allergic reactions such as skin rash.

The anthracene group of laxatives are physiologically attractive, since their stimulant action is mostly confined to the large bowel. However, only in the case of senna is a fully active, standardized preparation available, namely, Senokot. ${ }^{1}$ There are two forms: granules and tablets. The granules are prepared with a mixture of malt, cocoa, and sugar.

${ }^{1}$ Westminster Laboratories Ltd.
These are exceptionally palatable and can be of much value when it is necessary to conceal from the psychiatric patient that a drug is being given. Both granules and tablets are standardized in terms of sennosides $\mathrm{A}$ and $\mathrm{B}$.

Douthwaite and Goulding (1957) confirmed, by feeding high doses of Senokot to mice, that there was no evidence, either macroscopic or microscopic, of any irritant, i.e., inflammatory change in the gut, while Fairbairn (1958) showed that mice given large doses over a period of nine months continued to thrive with no sign of harmful effect. There appears to be no danger from the ingestion of large doses, always a risk with psychiatric patients, for Hawkins (1958) reports the case of a 7-year-old boy who consumed $2 \mathrm{oz}$. $(60 \mathrm{~g}$.) of the granules without any evidence of systemic toxicity.

Animal experiments have shown that the senna glycosides are first absorbed from the small intestine into the systemic circulation and re-excreted into the colon. Here they are broken down by enzyme action or intestinal flora to release the active principle, which presumably stimulates sensory receptors in the intestinal mucosa (Straub and Triendl, 1937; Okada, 1940), and through Meissner's and Auerbach's plexuses the intrinsic peristaltic reflex is produced. This physiological stimulation of intestinal peristalsis substantiates the claim that senna produces a good reproduction of normal peristalsis. Some analogy to the sensitizing action of 5-hydroxytryptamine would seem to be apparent.

Pharmacological studies (e.g., Lenz, 1924; LeBoeuf, 1949; Valette, 1949) and clinical reports (Braid, 1954; White and Dennison, 1958; CampbellMackie, 1959; Katz, 1960; Dubow, 1960; Coekin and Gairdner, 1960, and others) indicate that the essential action of Senokot is to increase the tone of the colonic musculature.

\section{WARD TRIALS}

Having decided upon the most suitable aperient, the aim of the second part of the investigation was to introduce it into ward routines in order to (1) judge the ability of the nursing staff, under medical direction, to deal satisfactorily with problems of constipation with only the selected aperient, and (2) examine its efficacy in the special problems peculiar to a mental hospital population.

The wards selected for the trial had all existing stocks of aperients withdrawn and Senokot in both granule and tablet form issued. There were 210 patients in this part of the study: the average dosage was one teaspoonful at night followed by two teaspoonfuls the following night if no evacuation had 
taken place. The granules were mixed with the bedtime milk to produce a pleasant chocolate drink and the patients were not informed that this was a laxative unless they asked. The purpose was to eliminate the psychological effect of drug taking so that the morning evacuation might become associated with a habit time rather than with the taking of a laxative. In the event, a number of patients who had relied on laxatives for many years required higher and more frequent doses of hidden Senokot before it was effective, and these patients were, therefore, given the drug in tablet form to begin with, this being replaced gradually with the granules until the patient found himself regular with the aid of the unidentified aperient. Once this had been achieved it was then possible to establish regularity on diminishing doses in a manner parallel with that of the other patients.

\section{RESULTS}

At the beginning of the study $44 \%$ were receiving aperients in any one week. By the end of the first month $31 \%$ had received aperients during the preceding week, and by the end of the second month the figure had been further reduced to $11 \%$. At the end of the third month the incidence was $20 \%$ but this included new patients recently transferred to those wards and only $8 \%$ of the original number were on a maintenance dose which, in most cases, was a sub-laxative one sufficient to maintain regular bowel action. These figures are similar to the findings of other investigators using Senokot. Flintan and Weeden (1953) found a 7\% failure rate with their sample, Lamphier and Ehrlich (1957) a $5 \%$ failure rate, and Wager and Melosh (1958) a 6\% failure rate. Those patients who suffered from chronic constipation and had a lifelong dependency upon regular medication with aperients, complained of abdominal cramps and transitory diarrhoea when the dosage was raised to three or four teaspoonfuls. With experience, the nurses found that by dividing the larger doses twice daily both griping and loose stools could be eliminated.

\section{REPLACEMENT OF ENEMAS}

Concurrently with the programme of ward studies, several individual studies were conducted on groups of patients who presented as special problems of constipation. The first group comprised 24 chronic psychotics who had been on twice-weekly soap enemas for many years. In the first month of the trial the regimen was changed to one enema weekly plus Senokot tablets in lieu of the other enema. Dosage was adjusted to suit individual requirements and at the end of four weeks the remaining enema was dis- pensed with in favour of Senokot. For these difficult cases tablets were used in preference to the granules as the ward studies had shown that patients conditioned to enemas required a more tangible alternative than that provided by the granules. This psychologically important fact was established by a paired trial in the form of a pilot study which showed that patients receiving Senokot in place of an enema required a higher dose in the form of granules than they did of tablets. In weaning patients from enemas, the four-week period was found to be extremely useful in enabling doses to be adjusted conscientiously: the weekly enema which had been retained for this period provided some support for the nursing staff and, at the same time, avoided the use of excessively large doses. During the second and subsequent months, enemas were discontinued altogether, and the dosage was gradually reduced in the hope that the group would be completely free of aperients. By the end of three months no fewer than 17 of the original 24 patients were regular and free of aperients, while seven still required a regular maintenance dose. Some of the 17 patients who achieved bowel regularity were given a sub-laxative dose on request.

\section{INSULIN PATIENTS}

The second individual study involved patients receiving psychiatric insulin treatment, 31 of whom complained of constipation. Twenty of these were selected for a long-term trial, having only recently begun this treatment, while the remaining 11 were investigated for as long as they were in the insulin unit. While this group required only minimal doses of standardized senna administered every four days, it was found impossible to dispense with the aperient altogether during the period in which insulin therapy was in progress, although once treatment had been completed it was found that bowel regularity continued without the need for further administration of the aperient. It had been suggested that freedom from constipation would not be obtained until treatment had been completed because of the interference with normal physiology involved in insulin metabolism, and this small-scale investigation supported the indication for concomitant regular doses of standardized senna during insulin therapy.

\section{PATIENTS SUFFERING FROM ORGANIC DISEASE}

Twenty-five patients suffering from various chronic organic conditions were studied. Twelve were in a post-encephalitic condition, three suffered from paraplegia, nine from general paralysis of the insane, and one from a residual intracranial pathology originating in a head injury. These patients had 
atypical problems of defaecation, six being incontinent of faeces and the others showing transitory phases of constipation or alternating phases of constipation and diarrhoea. The hypothesis was that the particular organic condition of these patients included interference with the functioning of the supraspinal or pudendal defaecation reflex, and although it was felt unlikely that a normal reflex could be established in such cases, a trial was undertaken to determine what measure of support could be achieved with standardized senna. Dosages varied according to the individual patient but in all cases were much higher than those required in the other groups. During the first month attempts were made to achieve regular defaecation, and to this end doses were given which were high enough to ensure a motion and these were determined from the trial and error period of the first week. A characteristic of this group was that no patient, except the post-traumatic case, complained of griping even at three times the average maximum dose and this enabled the nursing staff to give an adequate level of the aperient with confidence. The patience and perseverance of the ward staff deserve special commendation, as the first fortnight produced considerable incontinence in this group. This condition proved to be a necessary preliminary to the establishment of regularity in these patients for, until a short period of incontinence had been obtained, residual traces of the habits inculcated by a protracted enema routine appeared to exist and interfered with the retraining regimen. The period of incontinence seemed to have the effect of destroying, temporarily at least, the chronic dependence upon enemas and provided a neurological tabula rasa, to borrow a Cartesian term, upon which the new reflex habits engendered by the Senokot programme could be impressed. Of this group three patients in a post-encephalitic state and one suffering from general paralysis of the insane required regular maintenance doses of Senokot although none of the group had to revert to enemas. These four were the most intellectually deteriorated of the group, and from inspection there appeared to be some correlation between the time required to establish bowel regularity and the degree to which the intellectual capacities had been preserved. One characteristic of Senokot which was invaluable in the bowel re-education of patients suffering from organic disease was the narrow range of times between administration and evacuation. Although this has been given by Herland and Lowenstein (1957) as three to 12 hours (mean eight hours, standard deviation $2 \cdot 2$ hours) the figures for administration at night are more consistent. With the psychiatric sample of 50 patients in whom these times were studied accurately, the range obtained was seven to 12 (mean 8.7 hours, standard deviation 1.3 hours), although figures outside these limits were occasionally obtained with other patients. These figures compare very favourably with those given for other aperients.

By giving Senokot granules in the bedtime drink, the nursing staff were able to get the plegic patients positioned on the W.C. soon after waking, where they could remain until their bowels functioned, and this could only have been conveniently organized with an aperient possessing a predictable time of onset. Since this study was completed, Jarrett and Exton-Smith (1960) have described a method of treating faecal incontinence in elderly patients with neuropathology. The regimen consists of imposing a periodicity of bowel action by the alternate use, night and morning, of agents with opposite pharmacological effects, namely Senokot and an opiate (in this case, mist. kaolin et morph.).There is little doubt that such a regimen would have improved considerably the management of the cases in the early phase of the present study.

The results of the ward studies and the three special studies are summarized in Table VI.

\section{TABLE VI}

RESULTS OF TRIALS WITH STANDARDIZED SENNA IN PSYCHIATRIC PATIENTS

\begin{tabular}{lcccc} 
Study & $\begin{array}{l}\text { Sample } \\
\text { Size }\end{array}$ & $\begin{array}{l}\text { Number } \\
\text { Regular after } \\
\text { Senokot } \\
\text { Treatment } \\
\text { (Dosage } \\
\text { Discontinued) }\end{array}$ & $\begin{array}{l}\text { Number } \\
\text { Regular with } \\
\text { Maintenance } \\
\text { Doses of } \\
\text { Senokot }\end{array}$ & $\begin{array}{l}\text { Number } \\
\text { Requiring } \\
\text { Other Forms } \\
\text { of Treatment }\end{array}$ \\
\hline A & 210 & 193 & 17 & 0 \\
B & 24 & 17 & 7 & 0 \\
C (a) & 31 & 0 & 31 & 0 \\
(b) & 31 & 31 & 0 & 0 \\
D & 25 & 21 & 4 & 0 \\
Total cases & 321 & $262(81.6 \%)$ & $59(18.4 \%)$ &
\end{tabular}

Study A Mixed psychiatric patients possessing various problems of constipation, most of them on psychotropic drugs possessing constipating properties.

Study B A selected group of chronic psychotics with long-standing constipation problems and receiving twice-weekly enemas.

Study C A group of patients receiving insulin coma therapy whose constipation was considered to be a direct consequence of the treatment (a) during and (b) after.

Study D A group of organic psychotics whose bowel dysfunction was related to neuropathology.

\section{DISCUSSION}

The constipated psychiatric patient poses a special problem since there are a host of mental conditions which produce bowel dysfunction. In the patients studied here, psychogenic causes included the 
complete spectrum of psychosomatic mechanisms, ranging from the emotional turbulence of psychoneuroses to the psychomotor retardation of a psychotic depression.

In mental patients what is required is the complete re-education of the defaecatory reflex to such a degree that it will function regularly and independently of future psychogenic constipating processes. Therapy of this kind is based on the 'conditioning' technique first devised by Pavlov and now widely used in medical psychology under the name of 'behaviour therapy' (Eysenck, 1961). Early conditioning of bowel function when a young infant is pottrained long before the spinal nerves are sufficiently myelinated to provide conscious control is of this type.

Treatment of constipation by conditioning involves the establishment of a rhythm by first destroying existing associations with external conditioned stimuli, and reverting to the natural stimulus of a full bowel, reinforced by a temporal overlay. At the time of writing, Senokot is the only suitable preparation for this technique. Its ready concealment enables the laxative-evacuation relationship to be broken, and its time of action has close limits which enable habit formation to take place with comparative facility. Also important is its consistency of action, for without this, conditioning would be ineffective. Its primary advantage over other aperients must be, however, its neurophysiological mechanism, for by using the alimentary neural pathways of the autonomic nervous system it strikes at the very roots of psychogenic constipation.

However, in psychiatric patients where neuropsychological processes operate to produce bowel malfunction, or where chemotherapy produces constipation as a side-effect, these factors prevent the successful establishment of regularity without continuing medication. Even these patients, however, can be made regular with the aid of sub-laxative maintenance doses. Dosage requires adjustment since psychiatric patients in particular show a wide range of individual differences in sensitivity.

\section{REFERENCES}

Alvarez, W. C. (1948). An Introduction to Gastro-Enterology, 4th ed., p. 617. Hoeber, London.

Becker, G. L. (1952). The case against mineral oil. Amer. J. dig. Dis., 19, 344-348.

Braid, Frances (1954). The treatment of constipation in children. Med. Press, 231, 521-524.

Burgess, D. E. (1958). The treatment of constipation-A physiological approach. Pharm. J., 181, 337-340.

Campbell-Mackie, Mary (1959). The treatment of bowel dysfunction in infants and young children. Practitioner, 183, 732-736.

Cecil, R. L., and Loeb, R. F. (1959). Constipation. A Textbook of Medicine, 10th ed., p. 829. Saunders, London.

Coekin, M., and Gairdner, D. (1960). Faecal incontinence in children. Brit. med. J., 2, 1175-1180.

Coghill, N. F., McAllen, P. M., and Edwards, F. (1959). Electrolyte losses associated with the taking of purges investigated with aid of sodium and potassium radioisotopes. Ibid., 1, 14-19.

Douthwaite, A. H., and Goulding, R. (1957). Action of senna. Ibid., 2, 1414-1415.

Dubow, E. (1960). Constipation in infants and children. Arch. Pediat., 77, $261-267$.

Eysenck, J. H. (1961). Behaviour Therapy and the Neuroses. Pergamon Press, London.

Fairbairn, J. W. (1958). Action of senna. Brit. med. J., 1, 218.

Flintan, P., and Weeden, G. D. (1953). Standardized senna. Lancet, $1,497$.

Francillon, J. (1952). Un cas d'iléus d'origine thérapeutique. Lyon Chir., 47, 888-889.

Hawkins, D. B. (1958). Action of senna. Brit. med. J., 1, 281.

Herland, A. L., and Lowenstein, A. (1957). Physiologic rehabilitation of the constipated colon in pregnant women. Quart. Rev. Surg. Obstet. Gynec., 14, 196-202.

Hurst, A. F. (1937). Constipation. In The British Encyclopaedia of Medical Practice, ed. H. Rolleston, Vol. 3, pp. 376-384. Butterworth, London.

Jarrett, A. S., and Exton-Smith, A. N. (1960). Treatment of faecal incontinence. Lancet, 1, 925.

Katz, R. (1960). Evaluation of standardized senna in the treatment of refractory constipation. Med. Press, 243, 355-356.

Lamphier, T. A., and Ehrlich, R. (1957). Evaluation of standardized senna in the management of constipation. Amer. J. Gastroent., 27, $381-384$.

LeBoeuf, H. (1949). Sur le Mode d'Action des Purgatifs Anathraquinoniques. Thèse Doct. Pharmacie, Paris.

Lenz, E. (1924). Observations à la fenêtre abdominale "colique" du chat. Arch. int. Pharmacodyn., 28, 75-157.

Nobbs, K. L. G. (1960). Confusion in the elderly. Lancet, 2, 888-889.

Okada, T. (1940). Uber den Mechanismus der Sennaabführung. Tohoku J. exp. Med., 38, 33-44.

Straub, W., and Triendl, E. (1937). Theorie der Abführwirkung der Folia sennae und ihrer wirksamen Inhalstoffe. Arch. exp. Path. Pharmak., 185, 1-19.

Valette, G. (1949). Effet sur l'intestin isolé des glucides du séné (sennosides A et B) et de leurs produits d'hydrolyse. C.R. Soc. Biol. (Paris), 143, 74-76.

Wager, H. P., and Melosh, W. D. (1958). Management of constipation in pregnancy. Quart. Rev. Surg. Obstet. Gynec., 15, 30-34.

White, M., and Dennison, W. M. (1958). Constipation. Surgery in Infancy and Childhood, p. 196. Livingstone, Edinburgh. 